Revista Iberoamericana, Vol. LXX, Núms. 208-209, Julio-Diciembre 2004, 939-955

\title{
PRÁCTICA INTELECTUAL Y DISCURSO CRÍTICO EN LA TRANSICIÓN. PUNTO DE VISTA Y NOVOS ESTUDOS DEL CEBRAP
}

\author{
POR \\ Ana Cecilia Olmos \\ Universidade de São Paulo
}

INCERTIDUMBRES POLÍTICAS Y PERPLEJIDADES ÉTICAS

La izquierda representa siempre un tipo de insatisfacción frente al orden establecido, sostienen Heller y Feher (Anatomía 43). Esa insatisfacción "implica un presupuesto éticoemocional que le da su fuerza y la vuelve concreta”, especifica Flores d'Arcais (19). Por su parte, Zygmunt Bauman afirma que no puede haber izquierda sin "una positiva y efectiva crítica de las negligencias, retrocesos y mala administración en la implantación de la promesa cultural de una sociedad mejor, sin la convicción de que esta promesa cultural es viable y, en principio, realizable” (29). En esta línea de pensamiento, podemos afirmar que las formaciones de izquierda que nuclearon las revistas Punto de Vista ${ }^{1} \mathrm{y}$ Novos Estudos del Cebrap ${ }^{2}$ configuraron una insatisfacción ante el estado de las cosas y adquirieron su fuerza de un impulso ético-emocional que las llevó a ejercer una intervención

\footnotetext{
${ }^{1}$ Punto de Vista aparece en Buenos Aires en el contexto de una sociedad totalmente controlada por un Estado autoritario lo que la lleva a omitir cualquier declaración de intenciones y a apelar a estrategias de enmascaramiento discursivo durante los primeros números. Recién en el número 12 de la publicación, de julio-octubre de 1981, se presenta el primer editorial y el Consejo de Dirección comprendido por Beatriz Sarlo como Directora y el grupo de intelectuales que dio inicio a la revista: María Teresa Gramuglio, Carlos Altamirano, Hugo Vezzetti y Ricardo Piglia.

${ }^{2}$ El Cebrap (Centro brasileiro de análise e planejamento) fue organizado en São Paulo por un grupo de intelectuales que había sido expulsado de la universidad por las medidas impuestas por el Acto Institucional n.5 de la dictadura militar. A partir de 1969, este centro se suma al conjunto de institutos privados que en América latina funcionaron como espacios alternativos de producción y difusión del conocimiento en el área de las ciencias sociales. Entre las publicaciones del Cebrap se encuentran las series de Cadernos (1967-1984) y Estudos (1971-1980). En 1981, en un clima de relativa distensión política, el centro presenta el primer número de Novos Estudos con un editorial firmado por Roberto Schwarz en el que se explicita la intención de trabajar por una democratización exhaustiva de la sociedad brasileña. Es importante señalar que el consejo directivo del Centro no coincide con el consejo editorial de la revista que está integrado por Juárez Rubens Brandão Lopes (presidente, que en 1986 va a ser reemplazado por Francisco de Oliveira), Antônio Flávio de Oliveira Pierucci, Carlos Estevam Martins, Danielle Ardaillon, Francisco de Oliveira (secretario), Pedro Paulo Poppovic, Perseu Abramo, Roberto Schwarz y Vinícius Caldeira Brant. En ese año el director del Cebrap es Fernando Henrique Cardoso.
} 
crítica y a sostener una promesa cultural en las sociedades transicionales de la Argentina y del Brasil de los años ochenta.

Ahora bien, si el presupuesto que moviliza a la izquierda es de orden ético-emocional, su insatisfacción -señalan Heller y Feher- apela a las esperanzas del proyecto iluminista (Anatomia 43). En otras palabras, si el núcleo afectivo es inseparable de convicciones que no aceptan la desigualdad como principio de relación social, las estrategias de acción se buscarán en las potencialidades de un iluminismo histórico que hizo de la equidad y la justicia social el horizonte de toda intervención política y cultural. Es en este sentido que, en la década del ochenta, la intelectualidad de izquierda de estas revistas se proyectó desde la esfera cultural hacia el espacio público con el propósito de articular voluntades de participación y transformación de la sociedad. En efecto, en el contexto de la transición, ambas publicaciones respondieron a los lineamientos éticos e ideológicos de una izquierda democrática para reclamar la efectivización de los derechos civiles y asumir la tarea de recuperar un ejercicio de ciudadanía que había sido sustraído por severos y prolongados regímenes autoritarios.

Reiteradas veces se señaló que el trabajo de moldear una voluntad de obediencia social había sido el objetivo de los últimos gobiernos militares que, en Argentina y en Brasil, asumieron las formas más siniestras del autoritarismo. La atrocidad de esa experiencia histórica llevó a Punto de Vista y Novos Estudos a trabajar por la configuración de una ciudadanía crítica como instancia imprescindible para la restauración de una práctica política democrática. En otras palabras, frente a la inmovilidad social y política impuesta por las dictaduras, estas publicaciones trabajaron en la línea de valores que sostienen la fuerza transformadora de las instituciones y buscaron favorecer la constitución de una ciudadanía autoconsciente que hiciera de las virtudes cívicas -a saber, tolerancia, solidaridad, justicia, racionalidad comunicativa y prudencia- imperativos irrecusables (Heller y Feher A condição política 133-39). Esto se hace evidente en un abundante espectro de editoriales y artículos que cubre las páginas de las dos publicaciones y que despliega una insistente reflexión en torno a la necesidad de fortalecer los principios democráticos que deberían regir el funcionamiento de los ámbitos político, económico y cultural de las sociedades de la postdictadura. ${ }^{3}$

\footnotetext{
${ }^{3}$ Para el desarrollo de esta problemática en ambas revistas remitimos a los siguientes textos (indicamos autor, título, número de la publicación y año). De Punto de Vista: PEHESA, “¿Dónde anida la democracia?” 15 (1982); Carlos Altamirano, "La oposición en el socialismo real” 14 (1982); Osvaldo Guariglia, “¿Qué democracia?” 18 (1983); Beatriz Sarlo, “La izquierda ante la cultura: del dogmatismo al populismo” 20 (1984); “Una alucinación dispersa en agonía” 21 (1984); Carlos Altamirano,"Imágenes de la izquierda” 21 (1984); Juan Carlos Portantiero, "Socialismo y Democracia. Una relación difícil” 20 (1984); Emilio de Ipola y Juan Carlos Portantiero, "Crisis Social y pacto democrático” 21 (1984); Fernando Henrique Cardoso, "La democracia en América Latina” 23 (1985); Pietro Ingrao, “Contra la reducción de la política a la guerra” 20 (1984); José Nun, “La rebelión del coro” 20 (1984); “Democracia y Socialismo: ¿etapas o niveles?” 22 (1984); "Intelectuales: ¿Escisión o mímesis?” 25 (1985); "Elementos para una teoría de la democracia. Gramsci y el sentido común” 27 (1986); Carlos Altamirano,“El intelectual en la represión y en la democracia” 28 (1986); “La legitimidad democrática y los parecidos de familia” 31 (1987); Albert Hirschman, "Opiniones obstinadas y democracia” 35 (1989). Entre los editoriales de Novos Estudos, ver: Francisco de Oliveira, “O compromisso dos intelectuais” 3 (1982); Maria da
} 
En este punto, sin embargo, no podemos dejar de señalar que fue la ostensiva insistencia en ese discurso institucionalista lo que marcó el gesto pedagógico de ambos proyectos. La pedagogía, sabemos, habitualmente no alimenta posiciones críticas y ahí residió la paradoja de estas dos revistas en el contexto de la transición: trabajar por la constitución de un ciudadano libre al mismo tiempo que sus prédicas homogeneizaban líneas de acción, al punto de asumir, incluso, el riesgo de hacer del campo político un ámbito indiferenciado. Si distinguimos -como lo hacen Heller y Feher (113-14)- las tres esferas típicas de las sociedades modernas: la de lo cotidiano, la de las instituciones políticas y económicas y la de las ideas y prácticas culturales, podemos postular que la intención de ambas revistas fue proyectar, desde el ámbito cultural hacia las dos primeras esferas, visiones del mundo articuladas con exclusividad sobre la base de relatos democráticos. Es decir: en estas publicaciones la visión crítica de la sociedad no dejó de investirse del gesto pedagógico de la lúcida conciencia del ciudadano de izquierda en cuyo discurso parecían repercutir, aún, los resabios de una elocuencia que aspiraba a revelar una verdad que no podía ser percibida o enunciada por otros. ${ }^{4}$

Aunque la insistente prédica institucionalista de Punto de Vista y Novos Estudos nos remita al gesto pedagógico de una izquierda que, por esos años, se presentaba como una suerte de vanguardia de la virtud cívica, no podemos dejar de considerar que, al trabajar por la constitución de un espacio público democratizado, estas publicaciones dejaron la marca de la indignación frente a lo existente y revelaron, en la emocionalidad de sus proyectos, un movimiento dispuesto no sólo a superar el estado de las cosas sino, también, a escapar del fantasma de las izquierdas totalitarias. Este fantasma, que amenazaba el horizonte de estos proyectos, exigía que su intervención política y cultural pusiese en escena una práctica ética pensada en términos de autoexamen y redefinición crítica para

Conceição Tavares, “O FMI no país do Faz-de-Conta” 4 (1982); María Hermínia Tavares de Almeida, "É tempo de novos direitos" 2.2 (1983); Francisco de Oliveira, "Democracia o bestialização" 2.3 (1982); Roberto Schwarz, “Ausências” 9 (1984); José Arthur Giannotti, "Populismo revisitado" 13 (1985); Luiz Felipe de Alencastro, “74 neles, Brasil!” 15 (1986); Francisco de Oliveira, “Depois da paz, a guerra” 16 (1986); Francisco de Oliveira, "Homenagem a Stanislau Ponte Preta 17 (1987). Entre los artículos de análisis de la coyuntura política pueden considerarse: Fernando Henrique Cardoso. “Os anos Figueiredo” 1.1 (1981); María Herminia Tavares de Almeida, “Os democratas no fio da navalha”1.1 (1981); Eunice Ribeiro Durham, "Movimentos sociais. A construção da cidadania”10 (1984); Francisco de Oliveira, “Além da transição, aquem da imaginação” 12 (1985); Dossiê “Pacto social” 13 (1985); Francisco de Oliveira, “E agora PT?” 15 (1986); Antonio Flávio Pierucci, “O povo visto do altar: demofilia ou democracia?” 16 (1986); Dossiê "In memoriam Candido Procopio Ferreira” 17 (1987); Luiz Carlos Bresser Pereira, “A crise da Nova República” 23 (1989). A estos se suman los artículos del Grupo de Conjuntura Econômica do Cebrap, centrados en estudios específicos de economía, y otros que abren la problemática democrática a perspectivas latinoamericanas y europeas.

${ }^{4}$ Foucault afirma que la conciencia y la elocuencia eran los aspectos que definían la politización de un intelectual de vanguardia que "decía lo verdadero a quienes aún no lo veían y en nombre de aquellos que no podían decirlo", y agrega: "Ahora bien, lo que los intelectuales han descubierto después de la avalancha reciente, es que las masas no tienen necesidad de ellos para saber; saben claramente, perfectamente, mucho mejor que ellos; y lo afirman extremadamente bien” (89-85). 
evitar nuevamente el fracaso (Heller y Feher Anatomía). En este sentido, el pensamiento de izquierda que orientó estas revistas contempló el cambio y la movilidad de sus postulados para no caer en sesgos dogmáticos que le hicieran perder el carácter pretendidamente corrosivo de su intervención. Es así como en las mismas páginas dedicadas a la problemática de la democratización social se desdobla, en ambas publicaciones, una revisión crítica del ideario de izquierda que desmontó la perspectiva revolucionaria que guiara el pensamiento y la praxis política en décadas anteriores, tomó distancia con relación al curso histórico seguido por los socialismos reales de Europa oriental y, fundamentalmente, desarrolló una reflexión que buscaba articular el ideario socialista con los principios democráticos que había activado la coyuntura transicional.

En otras palabras, esta revisión crítica dejaba en claro que una reforma intelectual y política de la izquierda pasaba, en ese momento, por el cuestionamiento del marxismo en tanto lógica totalizadora que, de una manera poderosa y eficiente, había funcionado como modelo explicativo de lo social, lo político y lo cultural. Se trataba de denunciar el riesgo totalitario que implicaban las versiones adoctrinadas de un pensamiento que-como señala Hoppenhayn (150)- había sometido la pluralidad de lo social a visiones del mundo deterministas y cerradas. Lejos de la utopía de la sociedad perfecta, el autoexamen crítico que las formaciones de izquierda de Punto de Vista y Novos Estudos exponían en sus textos dejaba claro que los ideales de justicia y equidad social que siempre habían perseguido debían sostenerse, ahora, en una concepción de sociedad como "evento inestable" (Touraine 36-45), es decir, ajeno a cualquier principio central de orden, y en una definición de democracia como "una utopía de conflictos, de tensiones y de reglas para procesarlos" (de Ipola y Portantiero 15).

Para sintetizar, en el contexto de la transición, ambas publicaciones configuraron un espacio de disenso que aspiraba, por un lado, a generar debates en el seno ideológico de la izquierda a fin de evitar su desmantelamiento y, por otro, a intervenir en la coyuntura de la transición política de sus países proponiendo una interpretación de los acontecimientos que influyese en la opinión pública. ${ }^{5}$ Este doble movimiento ponía en relación el ámbito cultural con el dominio público y exigía que los intelectuales articulasen de forma coherente las respectivas prácticas: la de la esfera de las ideas y la de la política. De esta forma se redefinía el lugar de enunciación de su discurso crítico: ahora pensado sobre una línea de tensión entre la especificidad del saber y la intervención pública. Por cierto, estas formaciones de izquierda fueron sensibles a las consecuencias que la aproximación de estas prácticas implicaba y no dejaron de manifestar una acentuada preocupación por una cualidad ética en el desempeño intelectual. Buscando responder a esta inquietud, las revistas se encargan de señalar que los principios que dirigen el pensamiento y el accionar de un intelectual no constituyen un sistema cerrado y absoluto sino que, por el contrario, se fundamentan en una autonomía relativa que, abandonando las “respuestas automáticas”, le garantiza a los individuos la posibilidad y el derecho de definir por sí mismos los

\footnotetext{
${ }^{5}$ Consideramos que este doble movimiento que Pécaut reconoce en los intelectuales de izquierda brasileños que actuaron durante la transición puede ser pensado, en los mismos términos, con relación a los intelectuales argentinos del período. Cfr. Daniel Pécaut (250).
} 
postulados que orienten sus actos. ${ }^{6}$ Es decir, estos intelectuales configuraron una ética en la que la decisión individual asume una relevancia significativa y pasa a ser el fundamento que explica y justifica los desplazamientos políticos e ideológicos que la relación entre la reflexión teórica, la producción textual y la intervención pública, en algunos casos, llegaba a poner en evidencia. ${ }^{7}$ No resulta extraña esta posición si se piensa que junto con el ideario marxista revolucionario habían caído, también, todas las coacciones del compromiso que de él dependían y, sobre todo, si se tiene en cuenta que la complejidad y la movilidad del juego político de la transición eran sentidas como una amenaza permanente a cualquier aspiración de congruencia.

Pero más allá de los desplazamientos estratégicos que imponen períodos de alta inestabilidad política como son los de las transiciones, no se puede desconocer que la condición de elite de estas formaciones intelectuales también pone en alerta la radical determinación democrática que sostenían sus intervenciones en la esfera pública. Se trata de una condición de elite fundada en la posesión de un saber letrado que -como señala Chauí (Entrevista)- determina una localización social de privilegio que otorga un sesgo profundamente autoritario a la presencia pública del intelectual. Una intervención pública que Rama, varios años antes, no dudó en referirse a ella como un "flexible despotismo ilustrado” (3-10) que define la práctica del intelectual latinoamericano como un trabajo de intermediación entre el saber letrado y el campo político donde se procesan las demandas sociales. Trabajo de intermediación que hizo que Francisco de Oliveira, por ejemplo, hablara de los intelectuales de izquierda como los "ventrílocuos tecnocientíficos" de la clase media brasileña que, al hegemonizar el campo político de la transición, definía sus rumbos y condenaba al silencio a las fracciones sociales dominadas y totalmente excluídas por el sistema represivo de la dictadura. ${ }^{8}$

\footnotetext{
${ }^{6}$ Nos referimos a una ética de la autonomía en los términos en que la define Castoriadis (65-66): articulada a la institución de un régimen verdaderamente democrático. "Una autonomía de esta guisa -afirma el autor- sea en el plano individual como en el colectivo, no nos garantiza, evidentemente, una respuesta automática a todos los asuntos que la existencia humana plantea; aún tendremos que afrontar las condiciones trágicas que caracterizan la vida, el no siempre saber distinguir, ni individual ni colectivamente, dónde campea el bien y dónde el mal. Pero no estamos condenados al mal, como tampoco al bien, porque podremos volver atrás, individual y colectivamente, reflexionar sobre nuestros actos, retomarlos, corregirlos, repararlos”.

${ }^{7}$ En este sentido pueden interpretarse los discursos de autorepresentación intelectual que ambas publicaciones exponen en el trazado de linajes intelectuales a los que se afiliarían históricamente. Las referencias de Punto de Vista a Echeverría, Hernández, Martínez Estrada, FORJA o la revista Contorno, así como las de Novos Estudos a Sérgio Buarque de Hollanda, Caio Prado Júnior o Antonio Candido funcionan a la manera de conjuros ante los riesgos de un ejercicio intelectual que, a la intemperie de resguardos teóricos, ideológicos y/o académicos, debía asumir en la esfera pública desempeños pragmáticos que amenazaban, permanentemente, el deber ser de su práctica. Para un desarrollo más detenido de esta cuestión, ver Ana Cecilia Olmos (75-100).

${ }^{8}$ Dice Francisco de Oliveira no seu artigo “Além da transição, aquem da imaginação”: “Assim, os temas da controversia do discurso político nos últimos dez anos testemunham que foram físicos contra o Estado no debate sobre as centrais nucleares; economistas contra o Estado no debate sobre o modelo econômico; cientistas políticos contra o Estado no debate sobre o Estado de exceção; sociólogos contra o Estado no debate sobre o caráter concentracionista e excludente da sociedade afluente que o crescimento criou; ecologistas contra o Estado no debate sobre a depredação do meio ambiente; antropólogos contra o estado no debate sobre a questão indígena” (10).
} 
Recordemos que, superando las particularidades de estos contextos locales, Adorno (9) ya había señalado el dramatismo que la tarea de crítica cultural encierra cuando se ejerce desde un lugar de elite. Él apuntó la paradoja en la que se encuentra el crítico cultural al hablar, como si fuera la objetividad misma, de una entidad de la que él necesariamente participa, pero por encima de la cual se imagina ilustremente elevado. Y advierte: "todo aquel que juega la carta de la superioridad respecto de algo, tiene que sentirse siempre al mismo tiempo como miembro del edificio en cuyo último piso se encuentra”. Aunque esta tensión permanente entre cultura y discurso crítico llegue a afectar el contenido corrosivo del segundo, al punto que Adorno afirma que “los críticos también ayudan a tejer el velo”, durante la transición, nuestras revistas aspiraron -conservando el velo-al ejercicio de una razón crítica que caracterizó una modernidad cultural sostenida en una aguda reflexión sobre las dimensiones económica, política y estética de la sociedad.

\section{Literatura y Sociedad en transición: Beatriz Sarlo y Roberto Schwarz}

Ante el saldo de sociedades desintegradas por los efectos atomizadores del autoritarismo, nuestras revistas compartieron el propósito de una intervención cultural que no desestimaba los efectos políticos de la práctica crítica. Para esta intelectualidad de izquierda, la distancia entre el ejercicio de la crítica cultural y de la práctica política sufrió un efecto de "estrechamiento" (Panesi 49) que puede pensarse como una prolongación de experiencias anteriores que Punto de Vista recupera en una genealogía heredera de Contorno (1953-1959) y Los libros (1969-1976) y que Novos Estudos puede reconocer en títulos como Teoria e Prática (1967) y Argumento (1973). Desde un núcleo ideológico común, vinculado a una tradición moderna de crítica cultural marxista, Punto de Vista y Novos Estudos tradujeron el imaginario de izquierda que hegemonizara esos títulos precedentes en posiciones de valoración democrática, como una salida posible a las iniquidades de un capitalismo exacerbado. Pero, sobre todo, recuperaron de sus antecesoras una apertura disciplinaria para la reflexión cultural que subvirtió los límites de los dominios específicos del saber y superó las tradicionales clasificaciones de los objetos de estudio.

En efecto, en los años ochenta, ambas publicaciones rompen con la autorreferencia del saber especializado y ponen en circulación una reflexión crítica abierta y móvil que diluyó las fronteras disciplinarias a favor de un análisis que hacía de toda significación cultural un objeto intrincado, denso, atravesado por las lógicas de lo político, lo económico y lo tecnológico. Pensando su intervención en estos términos, vale decir, como el ejercicio de una crítica política de la cultura, Punto de Vista amplió el radio de reflexión sobre la literatura al vincularla a otros paradigmas disciplinarios, mientras que Novos Estudos no dejó de abrir una brecha para el debate de la literatura en la densidad discursiva de los análisis sociológicos, políticos y económicos. En esta oportunidad nos centraremos en las prácticas críticas de Beatriz Sarlo y Roberto Schwarz que estas publicaciones ponen en circulación.

Esa apertura disciplinaria puede leerse en el trabajo de reelaboración del discurso crítico literario que Punto de Vista lleva a cabo en los años ochenta. Reelaboración que pasa, entre otras cosas, por la incorporación de los presupuestos del pensamiento 
culturalista inglés como una tentativa de recuperar una dimensión histórica para la reflexión sobre la literatura que había sido abandonada a cambio del estructuralismo que, enclaustrado en las aulas universitarias, postulaba la autonomía de su objeto y multiplicaba hasta la exasperación sus relaciones internas (Panesi 10). Como señala Sarlo, se trataba de un discurso objetivante que tuvo un efecto profundo en las disciplinas literarias al "desprestigiar las perspectivas históricas que sufrieron la misma suerte de los sujetos: ser convenientemente amontonados con los desperdicios y restos del humanismo, el biografismo, las mentalidades, las intenciones y las influencias" (“Clío revisitada” 24). Sabemos que el estructuralismo en su propósito radical de "desnaturalizar” presupuestos literarios tradicionales llegó a los límites extremos de eliminar, drástica y definitivamente, al sujeto, la experiencia y la historia de su horizonte de reflexión y de centrarse en una hermenéutica cuya clave interpretativa era, con exclusividad, el propio lenguaje. Por cierto, esta hegemonía del estructuralismo en el campo de la crítica literaria no dejaba de tener sus implicaciones ideológicas y es Raymond Williams quien, en la entrevista que Punto de Vista le realizara, las explicita al afirmar que:

\begin{abstract}
En ciertas situaciones privilegiadas de educación y de separación de la sociedad, poseer una teoría que afirma que el análisis intelectual de un sistema autosuficiente es todo lo que importa, y lo que es en verdad significativo es este sistema autosuficiente, debe sin duda parecer tranquilizador, porque lo que en realidad configura una situación distanciada y privilegiada se reviste de normalidad y parece estar más allá de todo riesgo. Y creo que ésta es una de las razones de su popularidad académica. ("Raymond Williams y Richard Hoggart: sobre cultura y sociedad” 15)
\end{abstract}

En este lugar distante y garantizado de la reflexión teórica se había instalado la crítica literaria de los ámbitos universitarios durante los años sesenta y permaneció durante la década siguiente reduciendo "la aparente complejidad del texto a un juego de oposiciones maniquea”. Así lo recuerda Adolfo Prieto (22-25) en Punto de Vista al revisar el ingreso y la difusión de los principios estructuralistas en el campo de la crítica literaria argentina. En estrecha relación con el boom de la narrativa latinoamericana, el discurso crítico del país se había sumado a las nuevas tendencias teóricas que postulaban la autosuficiencia del discurso de y sobre la literatura. Prieto registra esta adhesión en los textos analíticos que en los años setenta publicaron Nicolás Rosa, Noé Jitrik, Jorge Lafforgue y Josefina Ludmer. Cuidadoso en el gesto de recuperar textos cuyas premisas teóricas, para esa fecha, ya habían sido totalmente desechadas por sus autores, Prieto no deja de hacer la salvedad de que "aunque pocos reprocharon a los practicantes de la nueva crítica su distanciamiento de la historia, muchos de estos practicantes se cuidaron muy bien de ignorarla por completo" y, a continuación, señala cierta “impaciencia que algunos neófitos empezaban a sentir por una crítica que se autorecortaba en el universo textual” (23).

Fue al margen del ámbito académico que algunos críticos literarios, ya expulsados de una universidad intervenida por el gobierno militar, se hicieron cargo de ese malestar que provocaba una crítica centrada en el inmanentismo textual y comenzaron a emancipar su discurso de la coerción del modelo lingüístico. En efecto, es en la producción de los mismos autores -Ludmer, Jitrik, Rosa- donde Prieto lee el pasaje a una posición 
posestructuralista, ${ }^{9}$ en tanto "variante que empieza a desinteresarse de la persecución de las estructuras y que busca sustituir el rol del observador metódico, distante, impersonal, por el del crítico que produce una escritura sobre la escritura del texto analizado”. Prieto recupera las ideas barthesianas de $S / Z$ para explicar esta nueva modalidad crítica que, asumiendo la imposibilidad de clausurar la palabra literaria, se incorporaba a un proceso de producción textual que “desborda al que se ofrece como objeto original de análisis”, que "no se apoya en las certidumbres de un cientificismo despojado ahora de sus seculares premisas de validación” y que "admite que por las grietas del viejo objetivismo se reintroduce el sujeto como instancia productiva con su bagaje ideológico y su carga histórica”. Aunque el autor reconoce los beneficios de esta desconfianza sobre el cientificismo en el campo de la crítica literaria, no se deja seducir por estas nuevas teorías en las que "la historia naufraga en la multiplicidad de discursos que cruzan en la orgía de los significantes liberados”. Para Prieto, el posestructuralismo se distanciaba escépticamente tanto de los parámetros científicos como del sentido progresivo de la historia, en síntesis, “de los discursos legitimadores con que la modernidad fundaba su utopía de liberación" (24).

Lo que nos interesa señalar es que en los años ochenta Punto de Vista activa una reflexión en torno al discurso crítico literario con el propósito de revertir ese desalojo de la historia que habían provocado las premisas estructurales (en sus dos versiones) y, también, como una forma de superar la insatisfacción que los intelectuales de la revista sentían ante los límites disciplinarios del pensamiento francés. Por esta vía, la revista buscaba responder a una pregunta que, insistente, traía a discusión los alcances y límites de los estudios de literatura. Preguntarse acerca de cómo leer la literatura, en un momento en que los lenguajes analíticos franceses imponían su presencia, significaba, en principio, cuestionar la autosuficiencia del texto y, fundamentalmente, pensar a la literatura como una práctica discursiva inserta en el marco más general de las prácticas significantes de la sociedad.

Es posible visualizar en los artículos de la revista la tensión que se establecía entre modalidades críticas que, desde parámetros lingüísticos, enfatizaban los aspectos formales o estructurales del discurso literario y aquellas otras que, al pensar la literatura desde aspectos menos particulares y específicos, la ponían en relación con el sistema global de la cultura. Por ejemplo, al abordar los presupuestos teóricos del formalismo norteamericano, Sarlo reconoce la utilidad de sus categorías analíticas referidas a una retórica de la ficción pero le critica el hecho de soslayar su carácter social e histórico. Y, al respecto, especifica que "la cuestión de la crítica nos remite primero a una poética y luego, con todas las articulaciones necesarias a una teoría de los productos artísticos y culturales” “¿Cómo leer literatura?” 5).

\footnotetext{
${ }^{9}$ Este pasaje se registra en los siguientes textos: Crítica y ficción (1970) y Los fulgores del simulacro (1987) de Nicolás Rosa; El fuego de la especie (1971), La memoria compartida (1982) y Los ejes de la cruz (1983) de Noé Jitrik; Nueva novela latinoamericana (1969-1974) de Jorge Lafforgue y Cien años de soledad. Una interpretación (1970) y Onetti, los procesos del relato (1977) de Josefina Ludmer.
} 
Es en este sentido que Sarlo interviene en el debate sobre la crítica literaria de esos años: denunciando la imposibilidad de pensar en una textualidad absolutamente autorreferida. En una reseña de 1982, del libro de David Viñas, Literatura argentina y realidad política, Sarlo destaca la pertinencia de una perspectiva crítica que inserta el discurso literario en la trama social y lo atraviesa con los discursos "de la ideología y, eventualmente, con las formas más explícitas de lo político” ( “La moral de la crítica” 21). Al leer el texto literario dentro del texto social, Viñas construye un nuevo objeto, "contaminado", que, contra la asepsia estructuralista, exige un abordaje crítico que opera por la "mezcla”. Para Sarlo, Viñas lee desde una perspectiva histórica, sociológica y política, pero no en el sentido de un método suplementario sino como horizonte absoluto de toda lectura interpretativa. Viñas "habla de lo que importa", afirma taxativamente la autora y, recuperando el Barthes de las Mitologías, define en la crítica de Viñas el deber ser de esta práctica: develar la supuesta naturalidad de las significaciones tradicionales, desenmascarar su sentido histórico, su carácter de código social.

Un año después, en 1983, Altamirano y Sarlo publicaban su libro Literatura/ Sociedad en el que postulaban la necesidad de abrir la reflexión a zonas menos especializadas del saber que pensasen a la literatura como una práctica discursiva inserta en un juego de interrelaciones sociales y al discurso teórico y crítico como una práctica significativa de carácter multidisciplinario. Precisamente a esta diversidad de abordajes apunta la conceptualización de "sociología de la literatura" que Punto de Vista usa en una época en que los estudios culturales aún no habían dominado la escena disciplinaria. Entendida como un "lenguaje inestable” (Gramuglio 12), heterogéneo y fragmentado, de límites difusos y zonas superpuestas, esta "sociología de la literatura” se cruzaba con disciplinas diversas (desde la filosofía a las ciencias sociales), se apropiaba de autores y reformulaba tendencias no siempre convergentes, componiendo un marco teórico heterodoxo que intentaba dar cuenta del carácter heterogéneo de la trama textual, de su historicidad y de la existencia del autor y del lector en tanto sujetos sociales imprescindibles al proceso de producción literaria.

Lejos de configurar un sistema, la propuesta de Altamirano y Sarlo trazaba recorridos teóricos y metodológicos diversificados que desbordaban los límites específicos de la crítica literaria. Resistir a modelos epistemológicos rígidos significaba, en los ochenta, construir objetos “contaminados” y asumir abordajes críticos de "mezcla” que, desde perspectivas históricas, sociológicas y políticas, cuestionasen el enclaustramiento de lo literario. Al respecto, Sarlo se preguntaba "si la fetichización del texto no ha producido discursos objetivantes más indiferentes a la especificidad artística que algunas incursiones históricas y sociológicas”, y agregaba:

No todo lo que interesa saber sobre la literatura o el arte puede encontrarse de manera exclusiva en las obras. Frente a ello sólo se me ocurren dos posibilidades: o declarar ese interés ilegítimo o buscar también en otra parte. No es completamente ilusorio que restos deleznables para una mirada puedan rendir su significación frente a otra. ("El saber del texto" 26) 
Los presupuestos de un discurso crítico de mezcla, que al pensar la literatura inserta en la trama de lo social activa una pluralidad de prácticas y saberes, no eran inéditos en la escena cultural brasileña de los años ochenta que tenía en Antonio Candido uno de sus más significativos representantes. La sociología, la antropología y la historia confluían en la reflexión de este crítico que no ignoraba que estas perspectivas disciplinarias podían llegar a ser tiránicas y deformadoras si eran aplicadas unilateralmente a los estudios de la literatura ya que llegaban a reducir la obra a un mero "producto" y a desconocer su "función” en el proceso cultural. Para evitar estos riesgos, Candido (16-17) afirma que la consideración de los "factores externos" a la obra sólo es legítima si se la somete al principio básico de la autonomía estética. En otras palabras, la forma literaria se antepone a todo elemento exterior, de tal modo que éste sólo puede significar en la medida en que un movimiento de "traducción estética” lo redefina en términos de configuración artística (Schwarz “Originalidade da crítica” 188). Por cierto, para el discurso crítico, esto implica un trabajo de identificación de mediaciones analíticas en la forma estética. Un presupuesto metodológico que se sostenía en un instrumental teórico marxista que permitía reformular los vínculos entre literatura y sociedad abandonando los torpes determinismos de las vulgarizaciones sociológicas e, inclusive, cuestionando las euforias de las teorías de la inmanencia textual que, por esos años, habían adquirido una considerable repercusión en el ámbito académico de Brasil. Con esta apretada síntesis de los presupuestos teóricometodológicos que Candido expuso en su Formação da literatura brasileira (1959) sólo pretendemos destacar que su reflexión crítica apuntaba a una modalidad de lectura que, al articular un "momento analítico" de la forma estética a un "momento crítico" que abordara su función en el proceso de la cultura, restauraba una concepción integradora de lo literario (Chiappini 157-67).

La propuesta de Candido encontró firme y consistente continuidad en uno de sus discípulos que sostuvo, metodológica y teóricamente, ese contrapunto entre forma literaria y proceso social: Roberto Schwarz. Su reflexión tiene en las relecturas de Machado de Assis uno de sus momentos más representativos y, durante los años ochenta, Novos Estudos publicó varios de sus estudios sobre el autor. ${ }^{10}$ Schwarz encuentra en las cegueras de la crítica precedente la vía de acceso a la obra machadiana e intenta desmontar condenas que parecían insuperables. Complejo, moderno, nacional y negativo son las condiciones que Schwarz le reconoce a Machado de Assis y buscará demostrarlo, tomando como punto de partida para su lectura las reiteradas acusaciones dirigidas contra una supuestamente endeble composición narrativa. La volubilidad del narrador de As memórias póstumas de Bras Cubas, antes vista como uno de los aspectos vulnerables de la novela, es presentada por Schwarz como "parte de uma composição rigorosa, que formaliza e expõe em sua conseqüência dinamismos decisivos da realidade brasileira” "“Complexo, moderno" 46). Erigido en principio formal de la novela, la ambivalencia del narrador domina el argumento, los personajes, los temas, el ritmo narrativo, la conducción de la

${ }^{10}$ Ver: Roberto Schwarz. “Complexo, moderno, nacional e negativo”, 1.1 (1981); “A velha pobre e o retratista”, 1.2 (1982); “Uma desfaçatez de classe”, 11 (1985); “O sentido histórico da crueldade em Machado de Assis”, 17 (1987). 
frase, la mezcla de estilos, en fin, controla -a la manera de una lógica implacable- todos los niveles de la composición narrativa. Dice Schwarz:

A dualidade de critério é constitutiva da forma e da inquietação do romance machadiano, ela é a hélice que o empurra -em direção do nada. A explicação, no caso, leva a circunstâncias nacionais. (44)

En efecto, un paso más allá del momento analítico formal de la lectura, Schwarz demuestra que la ambivalencia del narrador funciona como una transposición de los dilemas ideológicos de una oligarquía que a fines del siglo XIX se debatía entre la arbitrariedad de una sociedad esclavista y la norma liberal europea (referente cultural hegemónico de la época). Pero no se trata de una mera transposición: la dualidad de criterio, constitutiva de la forma de la novela machadiana, configuraría la denuncia tácita de esa incongruencia alarmante entre el modelo civilizador y el inculto paisaje local que, históricamente, alimentó el sentimiento brasileño de los contrastes culturales. Un juego de contrastes que, con matices, atraviesa el pensamiento brasileño y encuentra en Schwarz su formulación en términos de una dialéctica entre lo local y lo cosmopolita (Arantes 20).

Este desajuste ya había sido expuesto por Schwarz en su conocido ensayo de 1973 “As idéias fora do lugar”; un análisis que, articulado a las teorías dependentistas de la hora, leía en el plano estético la disparidad producida por la extraña coexistencia del régimen esclavista y el ideario liberal europeo. Disparidad que colocaba a la esfera de la cultura en una "posición alterada” que denunciaba no sólo su carácter ornamental sino, y sobre todo, los aspectos disonantes de una modernidad periférica.

Este desconcierto entre la esfera de la cultura y la sociedad, así como los peculiares mecanismos elaborados para su articulación (la servidumbre y el clientelismo) es la materia inmediata y natural del novelista quien deberá formular, en una determinada construcción narrativa, las mediaciones apropiadas para la estilización de la dinámica social. Es en este sentido de traducción estética de una determinada dinámica social que Schwarz lee la volubilidad del narrador de la novela de Machado de Assis. En el reverso de esa aparente inconsistencia de la composición narrativa se identifica la denuncia de un comportamiento de clase ambiguo, suspendido entre la arbitrariedad del propietario abastecido y el discurso esclarecido del liberalismo europeo. ${ }^{11}$

A diferencia de la novela realista analizada por Lúckacs que contraponía el individuo fuerte a la sociedad para exponer las contradicciones e injusticias del orden burgués, Machado de Assis expone la vida bien provista de las clases dirigentes brasileñas que sostenían un ideario liberal en el contexto de una sociedad esclavista con el propósito de acentuar la denuncia de esta incongruencia. Sin embargo, señala Schwarz, este gesto de censura del autor supera el ámbito local y adopta una posición de crítica negativa frente

\footnotetext{
${ }^{11}$ Dice Schwarz en su artículo “Complexo, moderno, nacional e negativo”: “...a lei da prosa machadiana seria algo como a miniaturización ou diagrama do vaivém ideológico da classe dirigente brasileira, articulada com o mercado e o progresso internacionais, bem como com a escravidão e o clientelismo locais. Um vaivém que resume o vexame pátrio, mas não se esgota nele, pois diz respeito também à história global de que o mesmo Brasil é parte efetiva, ainda que moralmente condenada: a norma burguesa no seu todo não se pauta pela norma burguesa” (50).
} 
a la cultura europea y sus pretensiones de progreso ilimitado al explicitar que si la inferioridad brasileña existe "o metro que a mede não é também inocente”.

Queda claro, entonces, que el procedimiento de lectura de Schwarz consiste en observar cómo una forma social se traduce en principio constructivo de la forma artística estilizando el desencuentro histórico de una cultura periférica con el modelo central hegemónico (Sussekind 96-109). Sobre las bases de un materialismo que exige de la interpretación literaria el reconocimiento de un principio constructivo de la narrativa como mediación históricamente especificada, la lectura de Schwarz puede no sólo identificar aspectos de la obra machadiana hasta el momento ignorados por la crítica sino, también, analizar los efectos estéticos e ideológicos de un desarrollo capitalista desnivelado. Seguramente, este discurso crítico se encuentra atravesado por las lecturas y reflexiones que Schwarz compartiera con los cientistas sociales paulistas que, puestos a revisar los grandes modelos interpretativos de los orígenes del Brasil contemporáneo, indujeron al crítico a preguntarse acerca de las implicaciones literarias de una modernidad periférica que aún no había elaborado la discordancia histórica de capitalismo y esclavitud. "Versión estética de una teoría sociológica” o "explicación sociológica de una evidencia estética”, el concepto de las "ideas fuera de lugar” que organizan las lecturas machadianas de Schwarz es otro ejemplo pertinente de estos préstamos, simbiosis y tensiones disciplinarias que caracterizaron el discurso crítico de los años ochenta (en entrevista de Haddad a Schwartz).

Por UNA CRÍTICA POLÍTICA DE LA CULTURA

Por lo expuesto hasta aquí, creemos haber dejado claro que para Sarlo y para Schwarz la literatura, en tanto discursividad social, no carece de un contenido de verdad, no escamotea un saber sobre lo real y tampoco niega una carga experiencial, sino que -lejos de explicitarlo todo en los modos de una representación de la transparencia- lo hace presente bajo la condición velada de la forma estética.

Al respecto, Schwarz dice que "se de fato a insistência na forma, na primazia da organização sobre os elementos de conteúdo serviu para distinguir a linguagem artística das demais, ela também permite o confronto e algo como uma competição entre as linguagens, devolvendo à literatura a dimensão de conhecimento que ela evidentemente tem" (Os pobres 7). Por su parte, Sarlo sostiene que "no hay muchos otros discursos que puedan trabajar como el arte, en un mundo laico y abandonado por los dioses, sobre los límites extremos, rodeando ese núcleo resistente y terrible que podría denominarse lo real” $\mathrm{y}$, recordando a Benjamin, especifica que la forma figurada que asume la verdad en la literatura "no restaura una totalidad a partir de fragmentos dispersos (empresa quizá imposible) pero sí construye tramas y constelaciones de sentido, que plantean lecturas diferentes y alternativas del orden de lo real, según una pluralidad de regímenes discursivos y de estrategias de desciframiento" ("El saber del texto” 7).

Según esta idea de literatura -como discurso que se abre a la interpretación en el espacio de la figuración de la verdad-nuestros autores no pueden dejar de concordar en el principio de una crítica alegórica para el análisis de la forma estética. Si, como señala Jameson (O método Brecht 171-79), la alegoría es una herida en el texto por la que circula 
una pluralidad de significaciones posibles, es evidente que tanto Sarlo como Schwarz conciben la práctica crítica como un movimiento de lectura que abre una distancia sutil en el interior de la obra para hacer emerger lo indecible. Sin embargo, tal vez sea precisamente a partir de este punto que los caminos críticos de Sarlo y Schwarz toman rumbos diferentes. Las lecturas frankfurtianas de Sarlo la llevan a adoptar una fuerte posición que privilegia la mediación y que hace de la fragmentación, el distanciamiento y lo incompleto las claves fundamentales para interpretar el vínculo entre la esfera estética y el dominio político; claves que abren la lectura crítica a una infinidad de posibilidades interpretativas. Por su parte, Schwarz no desconoce esa tradición del marxismo crítico ni las instancias mediadoras inherentes a toda representación pero, al centrar su referencia exclusivamente en una estructura de clase, hace pesar en sus análisis de objetos estéticos una voluntad totalizadora que, por momentos, suspende la noción de fragmentación y autonomía.

Por ejemplo, al abordar una serie de textos que, en la Argentina de la década del ochenta, tematizaban la aún punzante experiencia del exilio, Sarlo se detiene en algunos autores contraponiendo sus estéticas (“Una alucinación” 1-4). Por un lado, la poética transparente de Juan Gelman que, a través de "un yo nada elusivo, fechado, vinculado a nombres, a personas, a lugares”, explicitaba el dolor del desarraigo, agigantaba la memoria de lo abandonado y, bajo la consigna de no olvidar nada, intentaba, obsesivamente, dejar el registro afirmativo de un pasado irrecuperable. En el otro extremo, la narrativa de Héctor Tizón proponía una poética del fragmento y de lo elusivo para reconstruir una memoria que garantizase la superviviencia en el destierro. Sarlo no duda: contra el rigor de una memoria que detalla infernalmente lo perdido, opta por "un texto que decía algo nuevo sobre el exilio”, quizá porque -como aclara la autora- prefirió no hablar de él y apenas atinó a la producción fragmentaria de un recuerdo.

No es arbitraria esta opción estética de Sarlo y no responde exclusivamente a parámetros del gusto personal. Desde la “iluminación profana” de Benjamin, ella propone adoptar una "mirada política" que focalice "las disidencias, el rasgo oposicional del arte frente a los discursos (la ideología, la moral, la estética) establecidos” (“Una mirada política” 1-4). Esta mirada política, en su labor desagregadora, se niega a establecer cánones y, "suspensa en la trama de las excepciones”, reconoce en la ruptura y lo nuevo, su valor. Sin olvidar a Adorno, Sarlo afirma que "un intelectual (quizá debería agregar: de izquierda) presta sus ojos y sus oídos y se empeña en escuchar los rumores diferenciados de la sociedad, en el espacio del arte”. Al optar por la estética elusiva de la narrativa de Tizón en contraposición a "las páginas ensopadas de melancolía y de una reafirmación dura de las experiencias” de la poética de Gelman, Sarlo busca, en esos años, cuestionar las certidumbres estéticas y críticas en las que la intelectualidad de izquierda corría el riesgo de anquilosarse. En otras palabras, apuesta a opciones estéticas que desmantelen las lecturas cristalizadas y totalizadoras de una izquierda que había aspirado a hacer del campo cultural un espacio estético e ideológico homogéneo. "Intervenir en contra de la unificación, exhibiendo, frente a ella, el escándalo de otras perspectivas” es el horizonte de la "mirada política” que propone Sarlo como estrategia de una práctica crítica (y de una estética) en el ámbito cultural de la transición.

Es precisamente en un movimiento de lectura unificador y totalizador que parecen caer las lecturas que Schwarz realiza de la obra de Machado de Assis. Según lo expuesto, 
Schwarz sigue un procedimiento de crítica marxista que reconoce en la mediación un componente de la narrativa que transcodifica los fenómenos dispares de la realidad en una unidad estética y una visión totalizadora de lo social. ${ }^{12}$ En este sentido, sus lecturas machadianas -y por extensión su concepción de práctica crítica- apuntaría a una interpretación que, controlando la brecha textual por donde penetra una multiplicidad de significados posibles, revele hermenéuticamente la verdad encerrada en el dispositivo narrativo, esto es: un agudo sentimiento de injusticia de clase. Por cierto, estas apreciaciones recuperan una línea de lectura brasileña que, en diferentes momentos, intentó desmontar las operaciones críticas de Schwarz e insistió en el gesto reductor en el que caen sus lecturas de Machado de Assis al limitar el valor estético de la obra al poder de revelación de una verdad de las estructuras sociales. ${ }^{13}$

Candido afirmó, en uno de sus artículos, que la fuerza de la ficción proviene, sobre todo, de la convención que permite elaborar un mundo más allá del mundo ("Os brasileiros” 63). Por lo expuesto hasta aquí, podríamos decir que, desplazada con relación a esta idea, la práctica crítica de Schwarz busca en la literatura un acceso a la verdad del mundo. En otras palabras, lo que se torna conflictivo en el discurso crítico de Schwarz son los límites de esa convención literaria, ya que se espera de ella un saber que dé cuenta de la diferenciación y la desigualdad de la sociedad. Para Schwarz el sentido velado en la forma de la novela machadiana sólo puede ser la mímesis de la estructura social como complejo de la lucha de clases. Podríamos decir, entonces, que los caminos críticos de Schwarz recorren una distancia alegórica que enlaza los dos términos: literatura y sociedad, pero no dejan de limitar sus posibilidades significativas desconociendo para la narrativa su condición de fuente inagotable de sentidos que, como decía Benjamin, “conserva a força reunida em seu âmago e é capaz de, após muito tempo, se desdobrar” ( 276).

Los objetivos planteados para una crítica política de la literatura en Sarlo y Schwarz coinciden, sin embargo, las modalidades adoptadas para llevarla a cabo parecen diferenciarse. El discurso crítico de Sarlo, en esa inflexión que enfatiza el valor dado a la experimentación estética, remite permanentemente a sus lecturas frankfurtianas, mientras que -sabemos por el propio Schwarz- el grupo de lectura de El Capital no incorporó la radicalidad de Adorno y Benjamin, lo que derivó en “uma certa indiferença em relação ao valor de conhecimento da arte moderna, incluída a brasileira, a cuja visão negativa e problematizadora do mundo atual não se atribuía importância” (Seqüências 104). Como

\footnotetext{
${ }^{12}$ Dice Jameson: "as mediações constituem um instrumento do analista, por meio do qual a fragmentação e autonomização, a compartimentalização e a especialização das várias regiões da vida social (a separação, em outras palavras, entre forma ideológica e política, entre a religiosa e a econômica, o hiato entre a vida diária e a prática das disciplinas acadêmicas) ficam pelo menos localizadamente superadas quando de uma análise peculiar" ( $O$ inconsciente 36$)$.

${ }^{13}$ Nos referimos al artículo de Bento Prado Jr. "A sereia desmitificada” y al debate que Novos Estudos organiza con motivo de la publicaicón del libro de Schwarz Um mestre na periferia del capitalismo. En este debate participaron, además del propio Roberto Schwarz, Davi Arrigucci, José Arthur Gianotti, Luis Pasta, entre otros críticos brasileños y llama la atención los puntos de coincidencia con las críticas realizadas anteriormente por Prado Júnior. Cfr. "Machado de Assis : um debate”. Novos Estudos 29 (1991): 59-84
} 
ya señaló Neil Larsen, aunque Schwarz concuerda con la escuela de Frankfurt en las posiciones críticas frente a los valores degradados de la industria cultural, no comparte la postura esteticista radicalizada de esta vertiente marxista (155-64). Influenciado por las teorías económicas dependentistas que en los setenta denunciaron el avance desigual y combinado del capitalismo, para el crítico brasileño la desalienación sólo es posible a través de una revolución social. En otras palabras, la idea de práctica crítica en Schwarz pretende reunir rigor metodológico y militancia esclarecedora, la de Sarlo, en cambio, sostiene en primera instancia el principio de autonomía estética. Ambos buscaron ejercer, durante las transiciones de sus países, una misma crítica política de la cultura.

Si, como señala Nicolás Casullo (64-65), la noción de peligro e incluso de catástrofe es la que da relieve a la noción de cultura, podríamos afirmar que Punto de Vista y Novos Estudos trabajaron en el corazón de la catástrofe, en un momento histórico en el que la noción de cultura como "hora crítica" exigía una apuesta en la intervención. En este sentido, la crítica política de la cultura que estas revistas intentaron ejercer durante la transición buscó romper las barreras disciplinarias y cuestionar la legitimidad institucional de los saberes. No obstante, es preciso aclarar que si bien los abordajes culturales de ambas revistas fueron mixtos, diluyendo las fronteras disciplinarias, no llegaron a un radical cuestionamiento de la legalidad institucional en la que los saberes se sostienen. Las páginas de estas revistas no dejaron de privilegiar un concepto de cultura restringido -limitado al ámbito de lo letrado- en el que la experimentación estética era uno de los criterios centrales de selección de los objetos. Esto significa que en estas revistas no hubo lugar para la experiencia popular que fue desplazada, en alguna medida, por la condición universitaria de estos intelectuales insertos en un ámbito institucional con el que están en tensión pero que a la postre los legitima.

De todos modos, lo que nos interesa subrayar es que la transdisciplinariedad sostenida por Punto de Vista y Novos Estudos durante los años ochenta se fundaba en opciones epistemológicas ligadas a un materialismo crítico. Al respecto, Sarlo señala que su referencia fue la vertiente culturalista inglesa habiendo permanecido al margen de la versión americana y, junto con Schwarz, deja claro que estas perspectivas críticas de mezcla reconocen en América latina una práctica precedente que tiene en Candido y Rama sus más significativos representantes (Sarlo y Schwartz “Literatura y valor” 287).

En síntesis, durante la década del ochenta, estas publicaciones se mantuvieron ajenas a la disolución de un paradigmo crítico y la intervención cultural que ejercieron tuvo por objetivo irreductible hacer presente lo irracional del proyecto iluminista, sin desconocer que la razón crítica supone, en términos humanos, la única salida a la devastación, la injusticia y las víctimas que las dictaduras habían dejado como saldo.

Bibliografía

Adorno, Theodor. “La crítica de la cultura y la sociedad”. Prismas. Barcelona: Ariel, 1962. Arantes, Paulo. Sentimento da dialética na experiência intelectual brasileira. Dialética e dualidade segundo Antonio Candido e Roberto Schwarz. Rio de Janeiro: Paz e Terra, 1992. 
Bauman, Zygmunt. "La izquierda como contracultura de la modernidad”. AAVV. La invención y la herencia. La izquierda ante el fin del milenio. Cuadernos ARCISLOM 4 (nov.-dic. 1996).

Benjamin, Walter. Rua de mão única. São Paulo: Brasiliense, 1998.

Castoriadis, Cornelius. "Miseria de la ética tradicional”. AAVV La invención y la herencia. La izquierda ante el milenio. Cuadernos ARCIS-LOM 4 (nov.-dic. 1996).

Candido, Antonio. Formação da literatura brasileira. São Paulo, Martins Fontes, 4 ed. s/d.

Casullo, Nicolás. Modernidad y cultura crítica. Buenos Aires: Paidós, 1998.

Chauí, Marilena. Entrevista en Cult. Revista brasileira de literatura III/35 (junho, 2000).

Chiappini, Lígia. "Forma e história na crítica literária brasileira: a atualidade de Antonio Candido”. Leituras do ciclo. Ana Luiza Andrade, Maria Lúcia de Barros Camargo, Raúl Antelo, orgs. Florianópolis: Abralic/ Ed. Grifos, 1999. 157-167.

Foucault, Michel. Microfísica del poder. Madrid: La Piqueta, 1978.

Heller, Agnes y Ferenc Féhèr. A condição política pós-moderna. Rio de Janeiro: Civilização Brasileira, 1998.

Anatomía de la izquierda occidental. Barcelona: Península, 1985.

Hopenhayn, Martín. Ni apocalípticos ni integrados. Aventuras de la modernidad en América Latina. Santiago: FCE, 1995.

Jameson, Frederic. O método Brecht. Petrópilos/RJ: Editora Vozes, 1999. O insconsciente político. A narrativa como ato socialmente simbólico. São Paulo: Editora Ática, 1992.

Larsen, Neil. "La teoría crítica brasileña y la cuestión de los “Culture Studies”. Revista de Crítica Literaria Latinoamericana XX/40 (Lima-Berkeley, 2do. semestre de 1994): 155-164.

Olmos, Ana Cecilia. “Intelectuales, instituciones, tradiciones”. Territorios intelectuales. Pensamiento y Cultura en América Latina. Javier Lasarte, comp. Caracas: La nave va, 2001. 75-100.

Panesi, Jorge. Críticas. Buenos Aires: Norma, 2000.

Pecaut, Daniel. Os intelectuais e a política no Brasil. Entre o Povo e a Nação. São Paulo: Atica, 1990.

Prado Jr., Bento. “A sereia desmitificada”. Alguns ensaios. Filosofia, literatura, psicanálise. São Paulo: Ed. Max Limonad, 1985.

Sarlo, Beatriz y Carlos Altamirano. Literatura / Sociedad. Buenos Aires: Hachette, 1983.

Sarlo, Beatriz y Roberto Schwarz. "Literatura y valor”. Leituras do ciclo. Ana Luiza Andrade, Maria Lúcia de Barros Camargo y Raúl Antelo, orgs. Florianópolis: Abralic/ Ed. Grifos, 1999. 287-306.

Schwartz, Roberto. “Originalidade da crítica de Antonio Candido”. Nuevo Texto Crítico VII/14-15 (julio 1994 a junio1995): 175-191. O pai de família. Rio de Janeiro: Paz e Terra, 1978. (Org.). Os pobres na literatura brasileira. São Paulo: Brasiliense, 1983. Seqüências brasileiras. São Paulo: Companhia das letras, 1999. 
Artículos en las revistas estudiadas

Candido, Antonio. “Os brasileiros e a literatura latino-americana”. Novos Estudos 1/1 (1981): 58-68.

De Ipola, Emilio y Juan Carlos Portantiero. “Crisis social y pacto democrático”. Punto de Vista 21 (1984): 13-20.

Flores d'arcais, Paolo. “El individuo libertario”. Punto de Vista 62 (1998):15-21.

Oliveira, Francisco de. "Além da transição, aquem da imaginação”. Novos Estudos 12 (1985): 2-15.

Prieto, Adolfo. “Estructuralismo y después”. Punto de Vista 34 (1989): 22-25.

Rama, Ángel. “Argentina: crisis de una cultura sistemática”. Punto de Vista 9 (1980): 310.

Sarlo, Beatriz. “Clío revisitada”. Punto de Vista 28 (1986): 23-26.

“¿Cómo leer literatura? Algunas consideraciones sobre el formalismo norteamericano”. Punto de Vista 2 (1978): 3-5.

"El saber del texto". Punto de Vista 26 (1986): 6-7.

“La moral de la crítica”. Punto de Vista 15 (1982): 21-22.

"Raymond Williams y Richard Hoggart: sobre cultura y sociedad". Punto de Vista 6 (1979): 9-18.

“Una alucinación dispersa en agonía”. Punto de Vista 21 (1984): 1-4.

“Una mirada política. Defensa del partidismo en el arte”. Punto de Vista 27 (1986): $1-4$.

Schwarz, Roberto. “As idéias fora de lugar”. Estudos Cebrap (1973): 151-161.

“A velha pobre e o retratista”. Novos Estudos 1/2 (1982): 35-38.

“Complexo, moderno, nacional e negativo”. Novos Estudos 1/1 (1981): 45-50.

"O sentido histórico da crueldade em Machado de Assis”. Novos Estudos 17 (1987): 38-44.

“Uma desfaçatez de classe”. Novos Estudos 11 (1985): 40-48.

Sussekind, Flora. "Ou não? Reflexões parciais sobre a crítica de Davi Arrigucci e Roberto Schwarz”. Novos Estudos 20 (1988): 96-109.

Touraine, Alain. “O método da sociologia da ação: a intervenção sociológica”. Novos Estudos 1/3 (1982): 36-45. 